\title{
Review \\ The Immunological Role of Vascular and Lymphatic Endothelial Cells in Filarial Infections
}

\author{
Magdalena Elżbieta Wysmołek*, Ewa Długosz (D) and Marcin Wiśniewski
}

Citation: Wysmołek, M.E. Długosz, E.; Wiśniewski, M. The Immunological Role of Vascular and Lymphatic Endothelial Cells in Filarial Infections. Animals 2022, 12, 426. https://doi.org/10.3390/ ani12040426

Academic Editor: Elena

Chaves-Pozo

Received: 30 November 2021

Accepted: 7 February 2022

Published: 10 February 2022

Publisher's Note: MDPI stays neutral with regard to jurisdictional claims in published maps and institutional affiliations.

Copyright: (C) 2022 by the authors. Licensee MDPI, Basel, Switzerland. This article is an open access article distributed under the terms and conditions of the Creative Commons Attribution (CC BY) license (https:// creativecommons.org/licenses/by/ $4.0 /)$.
Division of Parasitology and Parasitic Diseases, Department of Preclinical Sciences, Institute of Veterinary Medicine, Warsaw University of Life Sciences-SGGW, 02-786 Warsaw, Poland; ewa_dlugosz@sggw.edu.pl (E.D.); marcin_wisniewski@sggw.edu.pl (M.W.)

* Correspondence: magdalena_wysmolek@sggw.edu.pl

\begin{abstract}
Simple Summary: The endothelium is a monolayer of cells forming a thin membrane that lines the inside of blood vessels. These cells release molecules that regulate vascular relaxation, contraction, and can control blood clotting and the immune response. During infections with filarial nematodes, common parasites of humans and animals, the endothelium is believed to play a key role in the communication between the host and the parasite, since the embryonic stage of filaroids is distributed in the bloodstream. Therefore, this review aims to gather research from different scientists in order to better understand the host immune response in infections with filarial nematodes.
\end{abstract}

Abstract: The embryonic stage of filarial nematodes, or microfilariae (Mf), shows daily and seasonal periodicity that requires their migration through blood vessels into the lungs, where they are sequestered when not circulating in the peripheral blood. Therefore, Mf and the host endothelium are likely in a permanent state of hide and seek. Interestingly, filarial nematodes co-cultured in media with a murine endothelial cell line survive eight times longer than those cultured in media alone. This suggests that the endothelium is an important element of the immune response in filarial nematodes, perversely promoting their survival in the host. In this review, we will focus on potential pathways involved in the relationship between filarial nematodes and the host endothelium, including the role of endothelial ICAM/VCAM/PECAM adhesion molecules, surface markers involved in the passage of Mf through host tissue, anti-thrombolic effects caused by the presence of filarial nematodes (including plasmins), endothelial cell proliferation (VEGF), and other aspects of the immune activation of the endothelium. The aim of this review is to merge the knowledge about the cross-talk between Mf of different filarial nematode species and endothelial cells (EC), thus allowing a better understanding of the mechanism of these parasitic infections.

Keywords: immune response; epithelial cells; endothelium; cross-talk filarial nematodes-endothelium; host-parasite interactions; Brugia malayi; Dirofilaria immitis; VEGF; plasmin; ICAM; VCAM; PECAM; CD31

\section{Introduction}

Parasitic filarial nematode infections are considered a rare disease; however, according to the World Health Organization (WHO), in 2017 alone there were 14.6 million people infected with onchocerciasis presented with skin disease and 1.15 million with vision loss [1]. Infection by Dirofilaria repens and Dirofilaria immitis is the leading cause of canine filariasis in Asia, Europe, and North America. These parasites are zoonotic, and an increasing number of infections of humans has been reported [2-4]. For example, 1200 human cases of Dirofilaria spp. infections were registered in the territory of the ex-USSR during the period of 1915-2016 [5], 40 cases were reported in Austria [6], and 1465 in Ukraine [7]. In the tropical regions of the world, lymphatic filariasis is primarily caused by Brugia malayi and Wuchereria bancrofti, and is a continuing problem as 859 million people in 50 countries worldwide remain at risk of infection, and 51 million people are estimated to be infected, 
according to the WHO [8]. Thus, extensive research on the development of vaccines against filarial nematodes is ongoing [9].

Filariasis includes vector-borne diseases caused by a group of roundworms called filarial nematodes. The pre-L1 larvae, called microfilariae (Mf), are taken up by blood-sucking insects during a blood meal. In a timescale of weeks, Mf molt in the arthropod until they reach the L3 stage, and are injected into the final host during a subsequent blood meal, where they reach maturity, copulate, and the females release Mf into the host bloodstream. There are three phenotypes of filariasis: lymphatic (Wuchereria bancrofti, Brugia malayi), subcutaneous (Onchocerca volvulus, Diforilaria repens), or serous cavity (Dirofilaria immitis). Briefly, lymphatic filariasis impairs the lymphatic system, which is characterized by lymphedema, elephantiasis, and, in men, swelling of the scrotum, called hydrocele; all of these lead to severe disability in humans. Onchocerciasis, also known as river blindness, is associated with dermatitis and can occur with a loss of sight in humans as a result of a strong inflammatory response against $O$. volvulus antigens migrating through the corneal endothelium. Finally, D. immitis mainly affects dogs and is a causative agent of heartworm disease, leading to heart failure in canines. Treatments in use can have efficacity against adult worms, such as diethylcarbamazine (DEC) [10,11], or show microfilaricidal activity, such as ivermectin [11-13]. Additionally, recent evidence suggests that tetracyclines have both microfilaricidal and macrofilaricidal effects against filaroids [14-16].

Many species of filarial nematode require the migration of Mf through blood vessels and into the lung capillaries during their daily or seasonal periodicities. This leads to permanent interactions between Mf and the host endothelial cells (EC). As a result, a complex relationship between host $\mathrm{EC}$ and the molecules of the invading filarial nematodes is established. Evans et al. observed that Mf co-cultured in media with a murine endothelial cell line survived eight times longer than those cultured in media alone. This suggests that the endothelium is an important element of the immune response to filaroids, perversely promoting their survival in the host [17]. The appearance of Mf in the bloodstream follows a circadian periodicity regulated by light. Mf reach their peak concentration in the peripheral blood during the hours when mosquitos are most likely to feed [18], which is supported by a finding from Hayasaki et al., who observed that $D$. immitis Mf show positive phototaxis toward infrared light [19].

The adhesion of leukocytes to vascular EC is a hallmark of the inflammation process and the host's defense against pathogens [20]. On the other hand, in non-inflamed tissues during homeostasis, vascular EC maintain blood fluidity, regulate blood flow, control vessel wall permeability, and quiesce circulating leukocytes, as reviewed by Yang et al. [21,22]. In light of the crucial importance of EC in response to bloodborne parasites, an understanding of parasite-EC interactions may elucidate the mechanisms of innate immunity during filariasis.

In this review, we will focus on four potential pathways involved in the relationship between filarial nematodes and host EC, including the role of endothelial intercellular adhesion molecule 1 (ICAM)/vascular cell adhesion protein 1 (VCAM)/platelet endothelial cell adhesion molecule 1 (PECAM, CD31) adhesion molecules, surface markers involved in the passage of Mf through host tissue, anti-thrombolic effects caused by the presence of filarial nematodes (including plasmins), endothelial cell proliferation (VEGF), and other aspects of the immune activation of the endothelium. The aim of this review is to merge the knowledge concerning different species of filarial nematodes' cross-talk with EC, thus allowing for a better understanding of the mechanism of these parasitic infections.

\section{Migration/Adherence}

ICAM-1, ICAM-2, VCAM-1, and CD31/PECAM-1 all belong to an immunoglobulin superfamily that is expressed on the surface of EC and plays a crucial role in migration and adherence in host-parasite cross-talk. CD31/PECAM-1 was firstly described by Muller et al. [23], and its role in trans-endothelial migration was more thoroughly evaluated a few years later [24-26]. ICAM [27] is not highly expressed in normal tissue, but inflammatory 
stimuli, such as tumor necrosis factor alfa (TNF $\alpha)$, interferon gamma (IFN- $\gamma$ ), and bacterial endotoxin, significantly upregulate its expression and cell surface localization [28]. Thus, the up-regulation of ICAM-1 production on the vascular endothelium permits leukocyte adhesion and represents an early stage in the migration of these cells into sites of tissue inflammation by extravasation $[29,30]$. Finally, the vascular cell adhesion molecule VCAM was first identified as a cytokine-inducible adhesion molecule on endothelium, mediating the interactions of EC with tumor cells and leukocytes [30-32]. These molecules interact with leukocyte counter-receptors to mediate the firm adhesion of leukocytes and their trans-endothelial migration in normally functioning endothelia during both homeostasis and inflammation [20]. Another important family of cell adhesion molecules is selectins, which bind sugar polymers, providing cell adhesion. As the leukocyte rolls along the blood vessel wall, the distal lectin-like domain of the selectin binds to certain carbohydrate groups presented on the proteins on the leukocyte, which slows the cell and allows it to leave the blood vessel to enter the site of infection. Selectins show a low-affinity binding that allows the characteristic "rolling" action attributed to leukocytes during the leukocyte adhesion cascade [33].

Importantly, adhesion to EC is not a property exclusive to host cells, but can also be presented by parasites, described sequentially in the next sections. Filarial nematodes, known for being masters of modulating the host immune response, likely use the upregulation of adhesion molecules expressed on the endothelium to freely move from the peripheral blood to the lungs' capillaries, with respect to their circadian periodicity [18]. Filarial nematodes also likely use adhesion molecules to not only bind, but also to modulate the populations of leukocytes that can transmigrate through the endothelium.

\subsection{Brugia malayi}

It has been reported that, in an athymic mouse infected with B. malayi, Mf adhered to EC with their anterior end [34] that was originally defined as a "hook" [35]. Since then, Schroeder et al. showed that live B. malayi Mf inhibit the in vitro trans-endothelial migration of neutrophils and monocytes, but not lymphocytes [36]. In the same paper, they also reported that, when the endothelium was exposed to Mf, the vascular EC expression of key mediators of the tethering stage of extravasation, such as ICAM-1 and VCAM-1, was unchanged. These studies concluded that the EC surface expression of VCAM-1, P-selectin, E-selectin, and ICAM-1 was not involved in Mf binding and the question around the mechanism of cross-talk between Mf and EC remained unresolved [36,37]. A few years later, Schroeder et al. observed that B. malayi Mf adhered to human umbilical vein endothelial cells (HUVEC) and TNF- $\alpha$ activated THP-1 cells, but not HEK 293 cells [38]. Further experiments involved HUVEC incubated with Mf in the presence of either complement C3-depleted human serum or untreated human serum. Schroeder et al. observed that the adherence of Mf to the endothelium was significantly decreased in C3-depleted serum compared to untreated serum, indicating that C3 plays a key role in Mf binding [38] (Figure 1). C3 depositions were detected on the surface of Mf co-cultured with intact serum, particularly concentrated at the anterior and posterior ends of Mf. Therefore, $\mathrm{C} 3 \mathrm{~b}$ and/or $\mathrm{iC} 3 \mathrm{~b}$ are suspected to bind to the microfilarial sheath in order to play a role as ligands for $\mathrm{C} 3$ receptors expressed on the endothelium. Furthermore, iC $3 \mathrm{~b}$ and Factor $\mathrm{H}$ (which can lead to $\mathrm{iC} 3 \mathrm{~b}$ formation) have been found on the surface of $\mathrm{Mf}$ from both O. volvulus and Loa loa after in vitro treatment with human serum $[39,40]$. Others have reported that $B$. malayi $\mathrm{Mf}$ secrete potent vasodilators, such as prostacyclin and prostaglandin E2 (PGE2), which may allow these parasites to modulate the vasculature function of the endothelium [41,42]. By showing that B. malayi Mf can bind to vascular EC in vitro, a hypothesis can be raised that the active adherence of $\mathrm{Mf}$ to EC may be a key mechanism by which Mf sequester in the lungs of the human host during times when mosquitos are not feeding $[18,43]$. As for periodicity, it has been reported that B. malayi Mf bind to the vascular EC under static conditions and under high, but not low, flow rates [38]. 


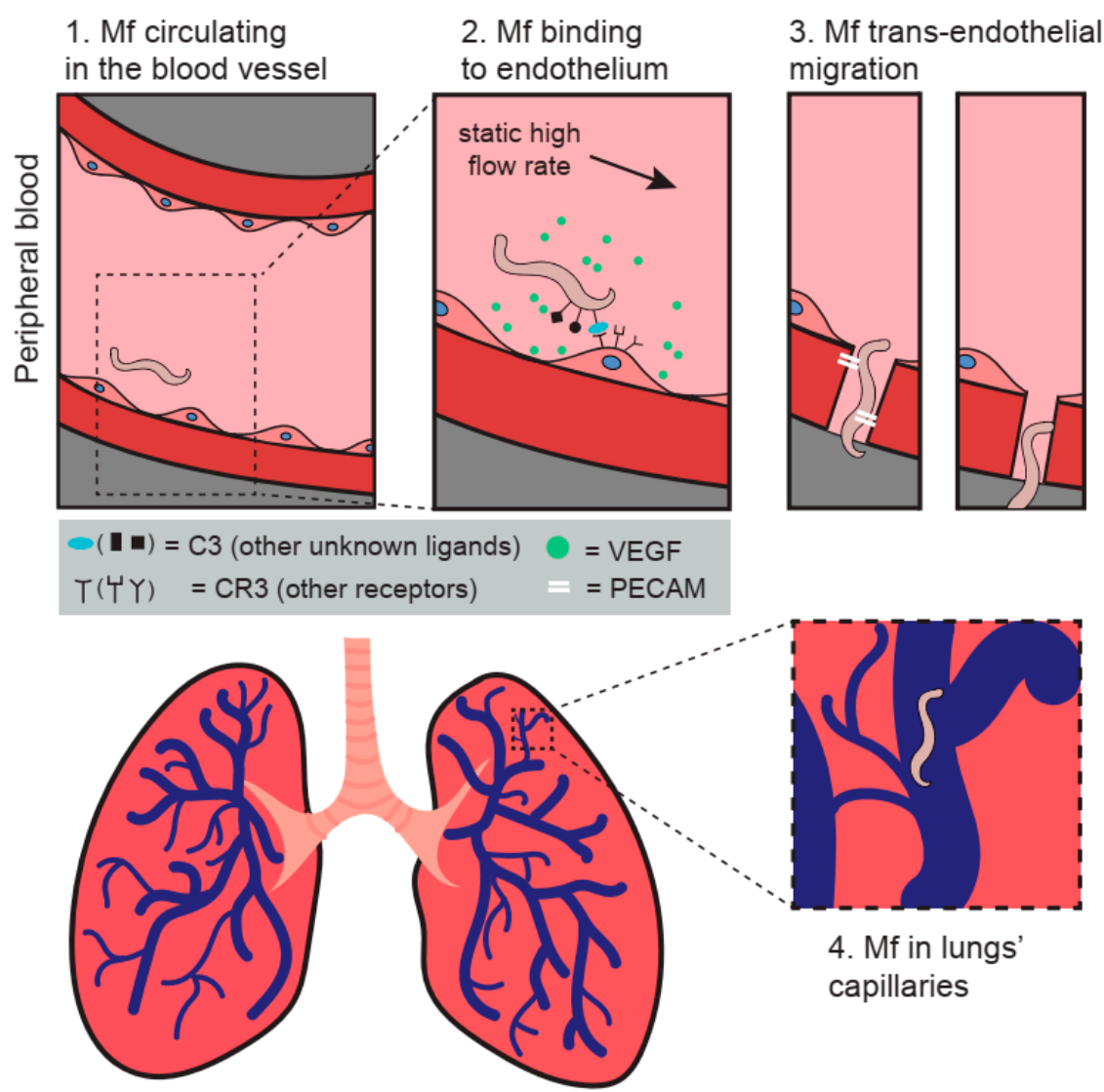

Figure 1. The figure presents a model of the potential trans-endothelial migration mechanisms adopted by Mf in the host. (1) Mf are circulating in the bloodstream during mosquito feeding time. (2) Increase in flow rate and the release of VEGF and likely other molecules promote the biding of Mf to the endothelium through complement component 3. (3) Mf trans-migration through the endothelium is likely enabled by CD31/PECAM-1. (4) Mf are sequestered in the lungs' capillaries in respect to their circadian periodicity. The figure was designed and created by MEW and Paulina Wysmołek.

Schroeder et al. also tested different stimuli that are believed to influence the periodicity of parasites, but neither the addition of melatonin (at concentrations analogous to the ones during sleep in humans), nor treatment with the antiparasitic drug diethylcarbamazine (DEC), nor a drop in temperature had a direct effect upon microfilarial binding to HUVEC in vitro. Only when the cells were incubated in a hypoxic environment was the adherence of Mf to the EC surface significantly lower [38].

Weinkopff and Lammie [44] investigated the effect of adult and Mf B. malayi excretorysecretory products (ES) on the activation of human lymphatic EC (hLEC). However, after implementing a variety of approaches, including cellular proliferation, cell surface molecule expression, and cytokine and growth factor production, they did not observe any direct effect of the parasites' proteins on the hLEC. Nevertheless, monocytes/macrophages exposed to filarial ES products secreted soluble VEGF that stimulated vessel growth associated with the pathogenesis of filarial disease [44].

\subsection{Ligmosoides sigmodontis}

Schroeder et al. [38] also tested if all Mf displayed the ability to adhere to EC or if it was reserved exclusively to periodic filarial nematodes. They observed that L. sigmodontis showed scarce adherence to HUVEC and no adherence to HEK 293T cell line.

\subsection{Wuchereria bancrofti}

Esterre et al. [45] compared the serum concentrations of soluble ICAM-1 and VCAM-1 in human patients suffering from lymphangitis of different origins-filarial or bacterial- 
but they did not observe any alterations specific only to lymphangitis related to $W$. bancrofti infection. However, in patients presenting elephantiasis or hydrocele, the levels of soluble L-selectin (leukocytes' cell adhesion molecule) were decreased, while the levels of ET-1 (endothelial vasoconstrictor) were increased.

\subsection{Onchocerca volvulus}

Kaifi et al. [46] determined the expression of cell adhesion molecules in response to onchocerciasis using a murine model in which the antigens from $O$. volvulus were injected into the corneal stroma. They reported that the expression of each of these molecules was elevated after the injection of parasite antigens; CD31/PECAM-1 and ICAM-1 expression remained elevated from $12 \mathrm{~h}$ after injection until 7 days, whereas VCAM-1 expression was more transient, with peak expression at $72 \mathrm{~h}$. After performing a VCAM- 1 blockade, they did not observe any significant difference in corneal opacification. However, they observed that CD31/PECAM-1 played an important role in the recruitment of neutrophils. On the other hand, the ICAM-1 blockade resulted in the impairment of eosinophils recruitment to the cornea. Therefore, they concluded that ICAM-1 has a selective role in eosinophil transmigration to the corneal stroma on the limbal vessels [46].

\subsection{Dirofilaria immitis}

As for D. immitis, Mf, as well as the adult stage of the parasite (that lives in canids' pulmonary arteries), are in constant contact with the host endothelium. The expression of ICAM-1 and CD31/PECAM-1, but not VCAM-1, was increased in human endothelial cells (HAAE-1) when treated with D. immitis adult somatic antigens [47].

Furthermore, Morchón et al. [47] compared the stimulatory capacity of adult somatic antigens of $D$. immitis (DiSA) and the recombinant form of their endosymbiont's proteinWolbachia surface protein (rWSP) - in in vitro cultures of vascular EC. Their results indicate a different stimulatory activity of the two antigens. Both DiSA and rWSP stimulate the production of the enzymes responsible for arachidonic acid metabolism, cyclooxygenase2, 5-lipoxygenase (5-LO), and leukotriene B4, but only DiSA stimulated the production of prostaglandin E2. As for the adhesion molecules, DiSA stimulated the expression of ICAM-1 and CD31/PECAM-1, whereas rWSP stimulated the expression of ICAM-1, CD31/PECAM-1, VCAM-1, and E-cadherin. Neither of the two antigens (DiSA nor rWSP) altered the basic physiological mechanisms of EC, such as cell proliferation, cell cycling, or apoptosis [48].

\section{VEGF/Cell Proliferation}

Vascular and lymphatic EC themselves can modulate the immune response by producing pro-inflammatory cytokines and chemokines, in addition to several angiogenic mediators, as reviewed by Shao et al. and Card et al. [49,50]. Vascular endothelial growth factors (VEGFs) [51] are signaling proteins upregulated during neovascularization and key mediators of angiogenesis, promoting increased vessel permeability and the inhibition of the host immune response [52].

Recent studies on the molecular mechanisms controlling the lymphatic vessels have shown that vascular endothelial growth factors (VEGF) specifically control lymphangiogenesis in humans by activating VEGF receptor-3, which is principally restricted to the lymphatic endothelium in adults. In animal models, the overexpression of VEGF-C in the skin of transgenic mice resulted in lymphatic endothelial proliferation and the dilation of lymph vessels with a resemblance to lymphatics infected with Mf. Additional evidence for the role of VEGF-C/VEGF-D/VEGFR-3 in the pathogenesis of lymphatic dilation and lymphedema stems from experimental studies in transgenic mice with skin-specific overexpression of soluble VEGFR-3 (sVEGFR-3) using a keratin 14 transgenic promoter. In this genetic model, sVEGFR-3 is secreted at high levels by basal epidermal keratinocytes and binds the lymphangiogenesis factors VEGF-C and VEGF-D, thereby preventing them from activating membrane-bound VEGFR-3 on lymphatic endothelium [53]. 


\subsection{Brugia malayi}

Live, intact Mf do not stimulate the expression of the angiogenic mediator VEGF-A in vascular EC, but they do stimulate an increase of pro-angiogenic COX-2 human lung microvascular endothelial cells [36]. Bennuru et al. showed that lymphatic EC proliferate in response to adult, but not microfilarial, antigens, and live parasites can induce tube formation by LEC in a contact-dependent manner. B. malayi microfilarial antigens also induced a number of angiogenic mediators in LEC [54]. Interestingly, Jeeva et al. detected a B. malayi Asparaginyl tRNA synthetase having properties identical to VEGF, leading to vascular EC proliferation, vasodilation, and angiogenesis [55].

In contrast, Rao et al. reported an in vitro treatment with fresh excretory-secretory products of adult $B$. malayi, particularly females, significantly suppressed the vascular endothelial proliferation of HUVEC [56]. They observed that the soluble extract of adult worms also decreased HUVEC proliferation, but less significantly than live adult excretorysecretory products. Interestingly, HUVEC treated with lymph from dilated lymphatics of mice infected with B. malayi demonstrated increased proliferation [56].

Tetracyclines were reported to have a strong anti-parasitic effect against filarial nematodes. Firstly, by acting against Wolbachia, an obligatory endosymbiont of filaroids. Secondly, Furlong-Silva et al. demonstrated by using a murine hind-limb model of filarial infection that doxycycline has anti-lymphangiogenic proprieties by blocking lymphatic EC proliferation in response to VEGF stimuli, which significantly reduces the magnitude of lymphatic remodeling and dysfunction induced by B. malayi filarial infection [9].

\subsection{Wuchereria bancrofti}

Although an increase in the expression of angiogenesis and lymphangiogenesis mediators in the sera of humans infected with $W$. bancrofti suggests that lymphatic filarial parasites may directly influence inflammation and angiogenesis, Mf antigens did not cause any significant increase or decrease in expression of VEGF-A, VEGF-C, VEGF-D, and VEGF-R measured by qPCR in vitro [54]. This may be due to the fact that Mf antigens, not live Mf, were used, since, in Polynesian patients living in regions endemic for W. bancrofti chyluria (a condition in which chyle is present in urine; mainly caused by Mf leading to the rupture of dilated abdominal lymphatics into the urinary excretory system), was associated with increased VEGF levels, whereas elephantiasis was characterized by an increase in endothelin-1 (ET-1) [45]. Another study showed that VEGF-A plays an important role in hydrocele in men [57], while VEGF-C and VEGF-D play a crucial role in lymphangiogenesis in both men and women [58,59] by activating the VEGF receptor-3 (VEGFR-3) [53,60]. It has been reported that a doxycycline-based treatment targeting Wolbachia in W. bancrofti decreased the plasma levels of VEGF-C/sVEGFR-3/VEGF-C, which improved the pathology in hydrocele patients $[53,61]$. On the other hand, Bennuru et al. reported that elevated plasma levels of VEGF-A, VEGF-C, VEGF-D, and angiopoietins (Ang-1/Ang-2) in both microfilaremic and in patients with lymphedema are associated with $W$. bancrofti infection, but not with Wolbachia itself, as they did not change after doxycycline treatment [62]. Finally, Panda et al. reported that a genetic polymorphism in endothelin-1 (a major angiogenic factor) was associated with elephantiasis or hydrocele in patients having clinical manifestations of the infection [63].

\subsection{Onchocerca volvulus (River blindness)}

There are several VEGF receptors (VEGFRs) expressed by the cornea that serve as "decoy" receptors for proangiogenic VEGF molecules. The corneal epithelium displays membrane-bound VEGFR-3 that binds and sequesters VEGF-C and -D. This directly suppresses lymphangiogenesis by inhibiting VEGF-C and -D-mediated signaling, and indirectly suppresses hemangiogenesis by inhibiting the recruitment of VEGF-secreting macrophages. Soluble VEGFR-1 and VEGFR-2 are essential for maintaining corneal avascularity under normal homeostatic conditions [64]. Unlike other VEGFs, VEGF-C cannot be upregulated by hypoxia, but only by proinflammatory cytokines [65]. Briefly, immune 
cells produce VEGF-C, which stimulates the proliferation of EC acting by VEGF-RC. This process is an important part of lymphangiogenesis, which in turn is significantly involved in the pathogenesis of blindness in onchocerciasis. Cao et al. observed that the injection of recombinant VEGF-C into limbal vessels stimulated neovascularization in mouse cornea in vivo [60]. The levels of the VEGF family and their receptors, Ang-1 and Ang-2, were significantly elevated in patients showing Onchocerca nodules in humans in vivo. Other scientists discovered that VEGFR-3 is expressed on corneal dendritic cells (DC) and is likely involved in leukocyte trafficking in the eye, which leads to the loss of vision in O. volvulus infections [66].

\subsection{Dirofilaria immitis}

Population-based studies demonstrated an inverse correlation between the number of circulating Mf and the proliferation [67,68]. Zueva et al. [69] created an in vitro model of heartworm disease using dog microvascular endothelial cells to test the effects of $D$. immitis adult antigens on EC. They observed an increase in the expression of proangiogenic factor VEGF-A and that recombinant WSP increased the expression of VEGF $[48,70]$. Zueva et al. stimulated EC with antigenic extracts from $D$. immitis adult worms obtained from dogs infected with $D$. immitis, from which one was treated with doxycycline in order to deplete Wolbachia before the experiment. Adult worms from the treated dog contained significantly lower amounts of Wolbachia (less than $60 \%$, tested by qPCR) compared to the worms removed from the untreated dog. Only worms from the untreated dog significantly increased the expression of the proangiogenic factor VEGF-A in the EC cultures. However, only worms from the doxycycline-treated dog significantly decreased the expression of the pro-angiogenic mEndoglin and increased the expression of the anti-angiogenic sEndoglin. The higher anti-angiogenic effects mounts of Wolbachia in the worms' antigens induced a proangiogenic response. Therefore, the authors concluded that $D$. immitis worms can stimulate angiogenesis and identified their endosymbiont bacteria, Wolbachia, as a key element in this process [69]. On the other hand, Zueva et al. reported one year later that recombinant surface protein of Wolbachia alone reduced the expression of mEndoglin (pro-angiogenic), increased that of sEndoglin (anti-angiogenic), and decreased the trend to the formation of pseudo-capillaries in dog microvascular ECs, which would suggest that this particular Wolbachia protein has an anti-angiogenic effect [70].

\subsection{Dirofilaria repens}

Ilyasov et al. detected a clear remodeling of the blood vessels, using Doppler, in the periphery of $D$. repens nodules in patients presented with subcutaneous dirofilariasis [71].

\section{Plasmin}

Tissue plasminogen activator (tPA) is an enzyme produced by, among others, EC that catalyzes the conversion of plasminogen to plasmin; thus, it is the major enzyme responsible for clot breakdown [72]. Plasmin can activate the lymphangiogenic growth factors VEGF-C and VEGF-D, and modulate the effects of VEGF [73]. Its upregulation is associated with inflammation, as it has been observed that tPA-deficient mice were resistant to post-trauma neuronal degeneration $[74,75]$. Additionally, plasmin was found to be involved in the M1 to M2 switch of macrophages [76,77].

The ability of plasmin to degrade fibrin, ECM, and connective tissues [78] facilitates the migration and invasion of parasites [79]. Furthermore, plasmin promotes the activation of the complement system, but degrades complement component 5 . This, on the other hand, prevents complement component $5 \mathrm{~b}$ deposition and membrane attack complex formation [79]. Furthermore, plasmin cleaves complement component $3 b$ to an inactive form, which prevents the formation of the terminal complement complex. Unfortunately, to date, there are no reports of whether Mf or adult filarial parasites employ this mechanism. However, it is potentially likely as Mf were found to be coated with C3b and/or iC $3 \mathrm{~b}$, as 
described in Section 2.1. Finally, it can be speculated that the recruitment of plasminogen on the worm's surface is a strategy enabling invasion and survival within the host.

\subsection{Dirofilaria immitis}

D. immitis ES upregulate tPA expression in HAAE-1 vascular endothelial cells $[80,81]$. These molecules, as well as surface-associated molecules and endosymbiont WSP protein, were shown to bind plasminogen and enhance its activation into plasmin [82,83]. Further, González-Miguel et al. [80,81] observed that DiES induce an increase in the expression of tPA in EC in vitro. The overproduction of plasmin (counteracting clot formation) promoted microvilli proliferation in the vessels in cardiopulmonary dirofilariasis. It is believed to be used as the parasites' survival mechanism and is likely beneficial for the host since it prevents clot formation [79].

\subsection{Brugia malayi}

In 1991, Foster et al. hypothesized that B. malayi Mf antigens release factors that inhibit the activation of hemostatic mechanisms [84]. In detail, they observed that Mf antigens completely inhibited the activation of factor XII and platelet aggregation.

\section{Cytokine Production}

Cytokines are known to play an important role in trans-endothelial migration. Nonetheless, there is a limited amount of research that investigated the endothelial cell-filaria cross-talk and, as such, in this review we will discuss the available data. For example, IL-10 suppresses the release of pro-inflammatory cytokines by immune cells [85]. Furthermore, it inhibits the growth of EC and endothelium-dependent $\mathrm{T}$ cell stimulation [86]. Interestingly, IL-10 was shown to be produced by human mononuclear cells and T cells challenged with $W$. bancrofti or Dirofilaria spp. antigens [87]. In humans infected with Wuchereria spp. or Dirofilaria spp., lymphocyte proliferation and activity against these parasites' antigens obtained from male and female adult worms were seen to be significantly lower [67].

TGF-B is produced by alternatively activated macrophages and T regulatory cells. Additionally, T cell clones isolated from peripheral blood of individuals with generalized onchocerciasis have a $\mathrm{T}$ regulatory cell phenotype $[88,89]$. As such, they selectively produce IL-10 and TGF- $\beta$, but not IL-2 $[88,89]$. Similarly, T regulatory cells were predominant in experimental models of filarial infection, as CD4+ cells showed elevated expression of CD25+, CTLA4, and glucocorticoid-induced TNFR-related protein (GIFR) [90]. Furthermore, in vivo injection of anti-CTLA4 and GIFR restored cytokine production and reduced parasite survival, consistent with the role of these cells in maintaining a state of immunotolerance [90].

Schroeder et al. [36] performed a wide screening of cytokines and chemokines produced by HUVEC in the presence of B. malayi Mf using culture supernatants for protein expression array. However, they did not observe Mf presence to have significantly altered the secretion of any molecules tested. Furthermore, the presence of live Mf did not seem to affect the proliferation of extravasated lymphocytes, T cells, CD8+, nor NK cells. However, Mf significantly inhibited the trans-endothelial migration of co-cultured neutrophils and monocytes [36].

To determine whether Wolbachia endosymbionts were responsible for any angiogenic mediator induction in EC, Schroeder et al. [38] cultured intact Mf or Wolbachia-depleted Mf with HUVEC. The results revealed that angiogenic factors were not altered in the presence of either intact Mf or Wolbachia-depleted Mf. Further investigations showed that, in the presence of Mf, neutrophils were more strongly attracted to HUVEC than lymphocytes [36].

In contrast to the effects provoked by the extracts of B. malayi Mf [91,92], Schroeder et al. [36] reported that live B. malayi $\mathrm{Mf}$ can initiate immune responses in their local vascular environment, and thus do not induce a significant increase of pro-inflammatory immune mediators from EC, such as IL-6, TNF- $\alpha$, or IL- $1 b$. Schroeder et al. also observed that live 
Mf did not induce increased levels of IL-13, known for promoting alternatively activated macrophages (AAMø), or the down-regulatory cytokines IL-10 or TGF-b1. However, Mf presence did induce the mRNA expression of the inflammatory complement component, C5, in HUVEC, but not human lung microvascular endothelial cells. On the other hand, both monocytes and neutrophils can kill Mf via the production of reactive intermediates. However, Mf can partially neutralize the toxic effects of these intermediates by secreting anti-oxidant enzymes, such as peroxidases and superoxide dismutase [36,92-95].

IL-8 and CCL2 are considered to be key chemokines for the trans-endothelial migration of neutrophils and monocytes [96]. However, Mf presence seems to have no effect on IL-8 or CCL2 production by EC [36]. This was confirmed by Weinkopff et al., who observed that filarial excretory-secretory products alone were not able to activate the LEC [97]. Further experiments performed by Weinkopff et al. showed that ES indirectly activate the LEC by inducing human peripheral blood mononuclear cells, specifically monocytes, to produce lymphangiogenic factors, such as IL-6, IL-8, and VEGF-A, which induce the formation of LVs in vivo [97].

Morchón et al. [98] also reported that the bacterial obligatory endosymbiont Wolbachia (detected in almost all species of filarial nematodes) plays an important role in the inflammatory pathology of filariasis. They reported an intense expression of mRNA of inducible nitric oxide synthase (iNOS) and increased production of intravascular NO (inflammatory mediator of the innate response), as well as IFN- $\gamma$ and a Th1-profile of antibody response in BALB/c mice immunized with the Wolbachia surface protein [98].

Finally, the parasite lives in the lymphatics of the mammalian host in close proximity to lymphatic endothelial cells, which are known to express iNOS and to generate prodigious quantities of NO in response to cytokines. The adult-stage antigen-specific immune response of immunocompetent mice can generate the requisite cytokines in response to specific filarial antigens and induce NO release in proximity to the parasite. This would explain the failure to resist $B$. malayi infection by wild-type mice treated with an inhibitor of NO synthase compared to complete resistance to infection in immunodeficient mice treated with a compound that releases NO demonstrated by Rajan et al. [99].

\section{Conclusions}

The intriguing interaction between filarial nematodes and the host vascular and lymphatic endothelium is a hallmark of filariasis in humans and animals. The endotheliumparasite crosstalk likely promotes the parasite survival and its potential transmigration through the blood wall vessel to the tissues' capillaries by increased expression of adhesion molecules, VEGF, and plasmin production. It seems that the parasites are able to inhibit the trans-endothelial migration of neutrophils and monocytes and promote the release of immunosuppressive cytokines, such as IL-10, which inhibit T cell activation.

In this review we discussed the effects of live parasites or their antigens on the host cells. Undeniably, live parasites allow a more precise and truthful observation of the parasites' pathological effect on the endothelium. However, the antigens of the adult parasites may allow an assessment of the process occurring while parasites die, and the use of a selected recombinant protein permits to study their proprieties as biotherapeutic agents. In order to evaluate host-parasite interactions, the use of live parasites is obviously the most relevant model, but not for all discussed parasites these data existed. Additionally, some studies separated and compared the effects of filarial nematodes containing their obligatory Wolbachia endosymbiont and Wolbachia-depleted worms on EC. These studies revealed that Wolbachia is likely involved in the promotion of angiogenesis [69].

The divergence of findings obtained by several groups is likely associated with the use of (1) excretory-secretory products from adult worms vs. Mf or (2) live adult worms vs. Mf (3) different cell lines from various species (human/murine/canine). In order to understand the true parasite-EC cross-talk, the use of live parasites of Mf embryo larval and adult stages challenging primary endothelial cells would allow for the most accurate assessment of the effects of filarial nematodes on EC. 
Author Contributions: M.E.W. conceptualized and wrote the manuscript; E.D. and M.W. critically revised the manuscript. All authors have read and agreed to the published version of the manuscript.

Funding: This research received no external funding.

Institutional Review Board Statement: Not applicable.

Informed Consent Statement: Not applicable.

Data Availability Statement: Not applicable.

Acknowledgments: The authors are grateful to Paulina Wysmołek for designing and creating the figure.

Conflicts of Interest: The authors declare no conflict of interest.

\section{References}

1. WHO. Onchocerciasis. Available online: https://www.who.int/news-room/fact-sheets/detail/onchocerciasis (accessed on 10 January 2022).

2. Dantas-Torres, F.; Otranto, D. Overview on Dirofilaria immitis in the Americas, with notes on other filarial worms infecting dogs. Vet. Parasitol. 2020, 282, 109113. [CrossRef]

3. Otranto, D.; Dantas-Torres, F.; Brianti, E.; Donato, T.; Dusan, P.; Genchi, C.; Capelli, G. Vector-borne helminths of dogs and humans-Focus on central and eastern parts of Europe. Parasites Vectors 2013, 6, 16. [CrossRef] [PubMed]

4. Genchi, C.; Kramer, L.H. The prevalence of Dirofilaria immitis and D. repens in the Old World. Vet. Parasitol. 2020, $280,108995$. [CrossRef] [PubMed]

5. Kondrashin, A.V.; Morozova, L.F.; Stepanova, E.V.; Turbabina, N.A.; Maksimova, M.S.; Morozov, E.N. Anthology of dirofilariasis in Russia (1915-2017). Pathogens 2020, 9, 275. [CrossRef] [PubMed]

6. $\quad$ Riebenbauer, K.; Weber, P.B.; Walochnik, J.; Karlhofer, F.; Winkler, S.; Dorfer, S.; Auer, H.; Valencak, J.; Laimer, M.; Handisurya, A. Human dirofilariosis in Austria: The past, the present, the future. Parasites Vectors 2021, 14, 227. [CrossRef] [PubMed]

7. Sałamatin, R.V.; Pavlikovska, T.M.; Sagach, O.S.; Nikolayenko, S.M.; Kornyushin, V.V.; Kharchenko, V.O.; Masny, A.; Cielecka, D.; Konieczna-Sałamatin, J.; Conn, D.B.; et al. Human dirofilariasis due to Dirofilaria repens in Ukraine, an emergent zoonosis: Epidemiological report of 1465 cases. Acta Parasitol. 2013, 58, 592-598. [CrossRef] [PubMed]

8. WHO. Lymphatic Filariasis. Available online: https://www.who.int/news-room/fact-sheets/detail/lymphatic-filariasis (accessed on 10 January 2022).

9. Kalyanasundaram, R.; Khatri, V.; Chauhan, N. Advances in Vaccine Development for Human Lymphatic Filariasis. Trends Parasitol. 2020, 36, 195-205. [CrossRef]

10. Hewitt, R.I.; Wallace, W.S.; White, E.; SubbaRow, Y. Experimental chemotherapy of filariasis: I. Experimental methods for testing drugs against naturally acquired filarial infections in cotton rats and dogs. J. Lab. Clin. Med. 1947, 32, 1293-1303. [CrossRef]

11. Moulia-Pelat, J.-P.; Nguyen, L.N.; Hascoet, H.; Nicolas, L. Associations de l'ivermectine et de la diéthylcarbamazine pour obtenir un meilleur contrôle de l'infection en filariose lymphatique. Parasite 1996, 3, 45-48. [CrossRef]

12. Campbell, W.C.; Fisher, M.H.; Stapley, E.O.; Albers-Schönberg, G.; Jacob, T.A. Ivermectin: A potent new antiparasitic agent. Science 1983, 221, 823-828. [CrossRef]

13. Wanji, S.; Eyong, E.E.J.; Tendongfor, N.; Ngwa, C.J.; Esuka, E.N.; Kengne-Ouafo, A.J.; Datchoua-Poutcheu, F.R.; Enyong, P.; Agnew, D.; Eversole, R.R.; et al. Ivermectin treatment of Loa loa hyper-microfilaraemic baboons (Papio anubis): Assessment of microfilarial load reduction, haematological and biochemical parameters and histopathological changes following treatment. PLoS Negl. Trop. Dis. 2017, 11, e0005576. [CrossRef] [PubMed]

14. Bajpai, P.; Srivastava, K.; Shakya, S.; Saxena, P.N.; Misra-hattacharya, S. Improvement in the efficacy of existing combination of antifilarials by inclusion of tetracycline in rodent model of Brugian filariasis. Curr. Sci. 2007, 92, 655-658.

15. Turner, J.D.; Langley, R.S.; Johnston, K.L.; Gentil, K.; Ford, L.; Wu, B.; Graham, M.; Sharpley, F.; Slatko, B.; Pearlman, E.; et al. Wolbachia lipoprotein stimulates innate and adaptive immunity through toll-like receptors 2 and 6 to induce disease manifestations of filariasis. J. Biol. Chem. 2009, 284, 22364-22378. [CrossRef] [PubMed]

16. Furlong-Silva, J.; Cross, S.D.; Marriott, A.E.; Pionnier, N.; Archer, J.; Steven, A.; Merker, S.S.; Mack, M.; Hong, Y.K.; Taylor, M.J.; et al. Tetracyclines improve experimental lymphatic filariasis pathology by disrupting interleukin-4 receptor-mediated lymphangiogenesis. J. Clin. Investig. 2021, 131, 140853. [CrossRef] [PubMed]

17. Evans, H.; Flynn, A.F.; Mitre, E. Endothelial cells release soluble factors that support the long-term survival of filarial worms in vitro. Exp. Parasitol. 2016, 170, 50-58. [CrossRef] [PubMed]

18. Hawking, F. The 24-h periodicity of microfilariae: Biological mechanisms responsible for its production and control. Proc. R. Soc. Lond. 1967, 169, 59-76. [CrossRef]

19. Hayasaki, M. Infrared light photobiostimulation mediates periodicity in Dirofilaria immitis microfilariae. J. Vet. Med. Sci. 2020, 82, 237-246. [CrossRef]

20. Granger, D.N.; Senchenkova, E. Leukocyte-Endothelial Cell Adhesion. In Inflammation and the Microcirculation; Morgan \& Claypool Life Sciences: San Rafael, CA, USA, 2010. 
21. Yang, X.Z.; Chang, Y.; Wei, W. Endothelial Dysfunction and Inflammation: Immunity in Rheumatoid Arthritis. Mediat. Inflamm. 2016, 2016, 6813016. [CrossRef]

22. Pober, J.S.; Sessa, W.C. Evolving functions of endothelial cells in inflammation. Nat. Rev. Immunol. 2007, 7, 803-815. [CrossRef]

23. Muller, W.A.; Ratti, C.M.; Mcdonnell, S.L.; Cohn, Z.A. A human endothelial cell-restricted, externally disposed plasmalemmal protein enriched in intercellular junctions. Cultured vascular endothelial cells (EC) 1 actively maintain a polarized distribution of integral membrane proteins between their apical. J. Exp. Med. 1989, 170, 399-414. [CrossRef]

24. Muller, W.A.; Weigl, S.A.; Deng, X.; Phillips, D.M. PECAM-1 is required for transendothelial migration of leukocytes. J. Exp. Med. 1993, 178, 449-460. [CrossRef]

25. Ferrero, E.; Elena, M.; Pardi, R.; Raffaella, M. To Endothelial Barrier Function. FEBS Lett. 1995, 374, 323-326. [PubMed]

26. Woodfin, A.; Voisin, M.B.; Nourshargh, S. PECAM-1: A multi-functional molecule in inflammation and vascular biology. Arterioscler. Thromb. Vasc. Biol. 2007, 27, 2514-2523. [CrossRef] [PubMed]

27. Rothlein, R.; Dustin, M.L.; Marlin, S.D.; Springer, T.A. A human intercellular adhesion molecule (ICAM-1) distinct from LFA-1. J. Immunol. 1986, 137, 1270-1274. [PubMed]

28. Springer, T.A. Adhesion receptors of the immune system. Nature 1990, 346, 425-434. [CrossRef] [PubMed]

29. Harlan, J.M. Leukocyte-Endothelial Interactions. Bloodf 1985, 65, 513-525. [CrossRef]

30. Hughes, R.C. Adhesive Glycoproteins and Receptors; Masson, S.A.S., Ed.; Elsevier: Amsterdam, The Netherlands, 1997; Volume 29, Chapter 14.

31. Osborn, L.; Hession, C.; Tizard, R.; Vassallo, C.; Luhowskyj, S.; Chi-Rosso, G.; Lobb, R. Direct expression cloning of vascular cell adhesion molecule 1, a cytokine-induced endothelial protein that binds to lymphocytes. Cell 1989, 59, 1203-1211. [CrossRef]

32. Elices, M.J.; Osborn, L.; Takada, Y.; Crouse, C.; Luhowskyj, S.; Hemler, M.E.; Lobb, R.R. VCAM-1 on activated endothelium interacts with the leukocyte integrin VLA-4 at a site distinct from the VLA-4/Fibronectin binding site. Cell 1990, 60, 577-584. [CrossRef]

33. Vinay, K.; Aster, A.K.A.; Jon, C.A. Robbins \& Cotran Pathologic Basis of Disease, 10th ed.; Elsevier: Amsterdam, The Netherlands, 2021

34. Kwa, B.H.; Buck, R.; Nayar, J.K.; Vickery, A.C. Cultured endothelial cells from lymphatics of nude mice parasitized by Brugia malayi. Lymphology 1991, 24, 22-25.

35. Laurence, B.R.; Simpson, M.G. Structure and taxonomy of microfilariae. Trans. R. Soc. Trop. Med. Hyg. 1969, 63, 428.

36. Schroeder, J.H.; Simbi, B.H.; Ford, L.; Cole, S.R.; Taylor, M.J.; Lawson, C.; Lawrence, R.A. Live Brugia malayi Microfilariae Inhibit Transendothelial Migration of Neutrophils and Monocytes. PLoS Negl. Trop. Dis. 2012, 6, e1914. [CrossRef] [PubMed]

37. Shen, J.; T-To, S.S.; Schrieber, L.; King, N.J. Early E-selectin, VCAM-1, ICAM-1, and late major histocompatibility complex antigen induction on human endothelial cells by flavivirus and comodulation of adhesion molecule expression by immune cytokines. $J$. Virol. 1997, 71, 9323-9332. [CrossRef] [PubMed]

38. Schroeder, J.H.; McCarthy, D.; Szestak, T.; Cook, D.A.; Taylor, M.J.; Craig, A.G.; Lawson, C.; Lawrence, R.A. Brugia malayi microfilariae adhere to human vascular endothelial cells in a C3-dependent manner. PLoS Negl. Trop. Dis. 2017, 11, e0005592 [CrossRef] [PubMed]

39. Meri, T.; Jokiranta, T.S.; Hellwage, J.; Bialonski, A.; Zipfel, P.F.; Meri, S. Onchocerca volvulus microfilariae avoid complement attack by direct binding of factor H. J. Infect. Dis. 2002, 185, 1786-1793. [CrossRef] [PubMed]

40. Haapasalo, K.; Meri, T.; Jokiranta, T.S. Loa loa Microfilariae evade complement attack in vivo by acquiring regulatory proteins from host plasma. Infect. Immun. 2009, 77, 3886-3893. [CrossRef] [PubMed]

41. Liu, L.X.; Serhan, C.N.; Weller, P.F. Intravascular filarial parasites elaborate cyclooxygenase-derived eicosanoids. J. Exp. Med. 1990, 172, 993-996. [CrossRef] [PubMed]

42. Liu, L.X.; Buhlmann, J.E.; Weller, P.F. Release of prostaglandin E2 by microfilariae of Wuchereria bancrofti and Brugia malayi. Am. J. Trop. Med. Hyg. 1992, 46, 520-523. [CrossRef]

43. Hawking, F.; Gammage, K. The periodic migration of microfilariae of Brugia malayi and its response to various stimuli. Am. J. Trop. Med. Hyg. 1968, 17, 724-729. [CrossRef]

44. Weinkopff, T.; Lammie, P. Lack of evidence for the direct activation of endothelial cells by adult female and microfilarial excretory-secretory products. PLoS ONE 2011, 6, e22282. [CrossRef]

45. Esterre, P.; Plichart, C.; Huin-Blondey, M.O.; Nguyen, L.N. Soluble cellular adhesion molecules, selectins, VEGF and endothelin-1 in patients with Wuchereria bancrofti infection and association with clinical status. Parasite Immunol. 2005, 27, 9-16. [CrossRef]

46. Kaifi, J.T.; Diaconu, E.; Pearlman, E. Distinct Roles for PECAM-1, ICAM-1, and VCAM-1 in Recruitment of Neutrophils and Eosinophils to the Cornea in Ocular Onchocerciasis (River Blindness). J. Immunol. 2001, 166, 6795-6801. [CrossRef] [PubMed]

47. Morchón, R.; Rodríguez-Barbero, A.; Velasco, S.; López-Belmonte, J.; Simón, F. Vascular endothelial cell activation by adult Dirofilaria immitis antigens. Parasitol. Int. 2008, 57, 441-446. [CrossRef] [PubMed]

48. Simón, F.; Morchón, R.; Rodríguez-Barbero, A.; López-Belmonte, J.; Grandi, G.; Genchi, C. Dirofilaria immitis and Wolbachia-derived antigens: Its effect on endothelial mammal cells. Vet. Parasitol. 2008, 158, 223-231. [CrossRef] [PubMed]

49. Card, C.M.; Yu, S.S.; Swartz, M.A.; Card, C.M.; Yu, S.S.; Swartz, M.A. Emerging roles of lymphatic endothelium in regulating adaptive immunity: Review series Emerging roles of lymphatic endothelium in regulating adaptive immunity. J. Clin. Investig. 2014, 124, 943-952. [CrossRef] [PubMed]

50. Shao, Y.; Saredy, J.; Yang, W.Y.; Sun, Y.; Lu, Y.; Saaoud, F.; Drummer, C.; Johnson, C.; Xu, K.; Jiang, X.; et al. Vascular Endothelial Cells and Innate Immunity. Arterioscler. Thromb. Vasc. Biol. 2020, 40, E138-E152. [CrossRef] [PubMed] 
51. Ferrara, N.; Houck, K.; Jakeman, L.; Leung, D.W. Molecular and biological properties of the vascular endothelial growth factor family of proteins. Endocr. Rev. 1992, 13, 18-32. [CrossRef]

52. Romanque, P.; Piguet, A.C.; Dufour, J.F. Targeting vessels to treat hepatocellular carcinoma. Clin. Sci. 2008, 114, 467-477. [CrossRef]

53. Debrah, A.Y.; Mand, S.; Specht, S.; Marfo-Debrekyei, Y.; Batsa, L.; Pfarr, K.; Larbi, J.; Lawson, B.; Taylor, M.; Adjei, O.; et al. Doxycycline reduces plasma VEGF-C/sVEGFR-3 and improves pathology in lymphatic filariasis. PLoS Pathog. 2006, 2, e92. [CrossRef]

54. Bennuru, S.; Nutman, T.B. Lympangiogenesis and Lymphatic Remodeling Induced by Filarial Parasites: Implications for Pathogenesis. PLoS Pathog. 2009, 5, e1000688. [CrossRef]

55. Jeeva, J.D.; Dhanraj, M.; Solaiappan, S.; Sivanesan, S.; Kron, M.; Dhanasekaran, A. Brugia malayi asparaginyl—Trna synthetase stimulates endothelial cell proliferation, vasodilation and angiogenesis. PLoS ONE 2016, 11, e0146132. [CrossRef]

56. Rao, U.R.; Zometa, C.S.; Vickery, A.C.; Kwa, B.H.; Nayar, J.K.; Sutton, E.T. Effect of Brugia malayi on the growth and proliferation of endothelial cells in vitro. J. Parasitol. 1996, 82, 550-556. [CrossRef] [PubMed]

57. Debrah, A.Y.; Mand, S.; Toliat, M.R.; Marfo-Debrekyei, Y.; Batsa, L.; Nürnberg, P.; Lawson, B.; Adjei, O.; Hoerauf, A.; Pfarr, K. Plasma vascular endothelial growth factor-A (VEGF-A) and VEGF-A gene polymorphism are associated with hydrocele development in lymphatic filariasis. Am. J. Trop. Med. Hyg. 2007, 77, 601-608. [CrossRef] [PubMed]

58. Korpelainen, E.I.; Alitalo, K. Signaling angiogenesis and lymphangiogenesis. Curr. Opin. Cell Biol. 1998, 10, 159-164. [CrossRef]

59. Achen, M.G.; Jeltsch, M.; Kukk, E.; Mäkinen, T.; Vitali, A.; Wilks, A.F.; Alitalo, K.; Stacker, S.A. Vascular endothelial growth factor $\mathrm{D}$ (VEGF-D) is a ligand for the tyrosine kinases VEGF receptor 2 (Flk1) and VEGF receptor 3 (Flt4). Proc. Natl. Acad. Sci. USA 1998, 95, 548-553. [CrossRef]

60. Cao, Y.; Linden, P.; Farnebo, J.; Cao, R.; Eriksson, A.; Kumar, V.; Qi, J.H.; Claesson-Welsh, L.; Alitalo, K. Vascular endothelial growth factor C induces angiogenesis in vivo. Proc. Natl. Acad. Sci. USA 1998, 95, 14389-14394. [CrossRef]

61. Debrah, A.Y.; Mand, S.; Marfo-Debrekyei, Y.; Batsa, L.; Pfarr, K.; Lawson, B.; Taylor, M.; Adjei, O.; Hoerauf, A. Reduction in levels of plasma vascular endothelial growth factor-A and improvement in hydrocele patients by targeting endosymbiotic Wolbachia sp. in Wuchereria bancrofti with doxycycline. Am. J. Trop. Med. Hyg. 2009, 80, 956-963. [CrossRef]

62. Bennuru, S.; Maldarelli, G.; Kumaraswami, V.; Klion, A.D.; Nutman, T.B. Elevated levels of plasma angiogenic factors are associated with human lymphatic filarial infections. Am. J. Trop. Med. Hyg. 2010, 83, 884-890. [CrossRef]

63. Panda, A.K.; Sahoo, P.K.; Kerketta, A.S.; Kar, S.K.; Ravindran, B.; Satapathy, A.K. Human Lymphatic Filariasis: Genetic Polymorphism of Endothelin-1 and Tumor Necrosis Factor Receptor II Correlates with Development of Chronic Disease. J. Infect. Dis. 2011, 204, 315-322. [CrossRef]

64. Stevenson, W.; Cheng, S.-F.; Dastjerdi, M.H.; Ferrari, G.; Dana, R. Corneal neovascularization and the utility of topical VEGF inhibition: Ranibizumab (Lucentis) vs. bevacizumab (Avastin). Ocul. Surf. 2012, 10, 67-83. [CrossRef]

65. Regenfuss, B.; Cursiefen, C. Concept of angiogenic privilege. Encycl. Eye 2010, 334-338. [CrossRef]

66. Hamrah, P.; Chen, L.; Zhang, Q.; Dana, M.R. Novel expression of vascular endothelial growth factor receptor (VEGFR)-3 and VEGF-C on corneal dendritic cells. Am. J. Pathol. 2003, 163, 57-68. [CrossRef]

67. Ottesen, E.A.; Weller, P.F.; Heck, L. Specific cellular immune unresponsiveness in human filariasis. Immunology 1977, 33, 413-421 [PubMed]

68. Brattig, N.W. Pathogenesis and host responses in human onchocerciasis: Impact of Onchocerca filariae and Wolbachia endobacteria. Microbes Infect. 2004, 6, 113-128. [CrossRef] [PubMed]

69. Zueva, T.; Morchón, R.; Carretón, E.; Montoya-Alonso, J.A.; Santana, A.; Bargues, M.D.; Mas-Coma, S.; Rodríguez-Barbero, A.; Simón, F. Angiogenic response in an in vitro model of dog microvascular endothelial cells stimulated with antigenic extracts from Dirofilaria immitis adult worms. Parasites Vectors 2019, 12, 1-7. [CrossRef]

70. Zueva, T.; Morchón, R.; Carretón, E.; Ollauri-Ibáñez, C.; Pericacho, M.; Rodríguez-Barbero, A.; Simón, F. Angiogenesis in cardiopulmonary dirofilariosis: Does the Wolbachia surface protein have a pro-or anti-angiogenic effect? J. Helminthol. 2020, 94, e162. [CrossRef]

71. Ilyasov, B.; Kartashev, V.; Bastrikov, N.; Madjugina, L.; González-Miguel, J.; Morchón, R.; Simón, F. Thirty cases of human subcutaneous dirofilariasis reported in Rostov-on-Don (Southwestern Russian Federation). Enferm. Infecc. Microbiol. Clin. 2015, 33, 233-237. [CrossRef]

72. Astrup, T.; Permin, P.M. Fibrinolysis in the animal organism. Nature 1947, 159, 681. [CrossRef]

73. McColl, B.K.; Baldwin, M.E.; Roufail, S.; Freeman, C.; Moritz, R.L.; Simpson, P.J.; Alitalo, K.; Stacker, S.A.; Achen, M.G. Plasmin activates the lymphangiogenic growth factors VEGF-C and VEGF-D. J. Exp. Med. 2003, 198, 863-868. [CrossRef]

74. Tsirka, S.E.; Rogove, A.D.; Strickland, S. Neuronal cell death and tPA. Nature 1996, 384, 123-124. [CrossRef]

75. Tsirka, S.E.; Gualandris, A.; Amaral, D.G.; Strickland, S. Excitotoxin-induced neuronal degeneration and seizure are mediated by tissue plasminogen activator. Nature 1995, 377, 340-344. [CrossRef]

76. Vago, J.P.; Sugimoto, M.A.; Lima, K.M.; Negreiros-Lima, G.L.; Baik, N.; Teixeira, M.M.; Perretti, M.; Parmer, R.J.; Miles, L.A.; Sousa, L.P. Plasminogen and the plasminogen receptor, PLG-RKT, regulate macrophage phenotypic, and functional changes. Front. Immunol. 2019, 10, 1458. [CrossRef] [PubMed] 
77. Sugimoto, M.A.; Ribeiro, A.L.C.; Costa, B.R.C.; Vago, J.P.; Lima, K.M.; Carneiro, F.S.; Ortiz, M.M.O.; Lima, G.L.N.; Carmo, A.A.F.; Rocha, R.M.; et al. Plasmin and plasminogen induce macrophage reprogramming and regulate key steps of inflammation resolution via annexin A1. Blood 2017, 129, 2896-2907. [CrossRef] [PubMed]

78. Gebbink, M.F.B.G. Tissue-type plasminogen activator-mediated plasminogen activation and contact activation, implications in and beyond haemostasis. J. Thromb. Haemost. 2011, 9, 174-181. [CrossRef] [PubMed]

79. Ayón-Núñez, D.A.; Fragoso, G.; Bobes, R.J.; Laclette, J.P. Plasminogen-binding proteins as an evasion mechanism of the host's innate immunity in infectious diseases. Biosci. Rep. 2018, 38, BSR20180705. [CrossRef] [PubMed]

80. González-Miguel, J.; Morchón, R.; Carretón, E.; Montoya-Alonso, J.A.; Simón, F. Can the activation of plasminogen/plasmin system of the host by metabolic products of Dirofilaria immitis participate in heartworm disease endarteritis? Parasites Vectors 2015, 8, 194. [CrossRef] [PubMed]

81. González-Miguel, J.; Morchón, R.; Siles-Lucas, M.; Simón, F. Fibrinolysis and proliferative endarteritis: Two related processes in chronic infections? The model of the blood-borne pathogen Dirofilaria immitis. PLoS ONE 2015, 10, e0124445. [CrossRef] [PubMed]

82. González-Miguel, J.; Morchón, R.; Carretón, E.; Montoya-Alonso, J.A.; Simón, F. Surface associated antigens of Dirofilaria immitis adult worms activate the host fibrinolytic system. Vet. Parasitol. 2013, 196, 235-240. [CrossRef]

83. Diosdado, A.; Gómez, P.J.; Morchón, R.; Simón, F.; González-Miguel, J. Interaction between Wolbachia and the fibrinolytic system as a possible pathological mechanism in cardiopulmonary dirofilariosis. Vet. Parasitol. 2017, 247, 64-69. [CrossRef]

84. Foster, C.B.; Flanigan, T.P.; Kazura, J.W.; Dumenco, L.L.; Ratnoff, O.D. Inhibition of the activation of Hageman factor (factor XII) and of platelet aggregation by extracts of Brugia molayi microfilariae. J. Lab. Clin. Med. 1991, 117, 344-352. [CrossRef]

85. Lisinski, T.J.; Furie, M.B. Interleukin-10 inhibits proinflammatory activation of endothelium in response to Borrelia burgdorferi or lipopolysaccharide but not interleukin-1 $\beta$ or tumor necrosis factor $\alpha$. J. Leukoc. Biol. 2002, 72, 503-511. [CrossRef]

86. Gleissner, C.A.; Zastrow, A.; Klingenberg, R.; Kluger, M.S.; Konstandin, M.; Celik, S.; Haemmerling, S.; Shankar, V.; Giese, T.; Katus, H.A.; et al. IL-10 inhibits endothelium-dependent T cell costimulation by up-regulation of ILT3/4 in human vascular endothelial cells. Eur. J. Immunol. 2007, 37, 177-192. [CrossRef] [PubMed]

87. Pearlman, E.; Hall, L.R. Immune mechanisms in Onchocerca volvulus-mediated corneal disease (river blindness). Parasite Immunol. 2000, 22, 625-631. [CrossRef] [PubMed]

88. Doetze, A.; Satoguina, J.; Burchard, G.; Rau, T.; Löliger, C.; Fleischer, B.; Hoerauf, A. Antigen-specific cellular hyporesponsiveness in a chronic human helminth infection is mediated by $\mathrm{T}(\mathrm{h}) 3 / \mathrm{T}(\mathrm{r}) 1$-type cytokines IL-10 and transforming growth factor-beta but not by a $\mathrm{T}(\mathrm{h}) 1$ to $\mathrm{T}(\mathrm{h}) 2$ shift. Int. Immunol. 2000, 12, 623-630. [CrossRef] [PubMed]

89. Hoerauf, A.; Satoguina, J.; Saeftel, M.; Specht, S. Immunomodulation by filarial nematodes. Parasite Immunol. 2005, 27, 417-429. [CrossRef]

90. Taylor, M.D.; LeGoff, L.; Harris, A.; Malone, E.; Allen, J.E.; Maizels, R.M. Removal of Regulatory T Cell Activity Reverses Hyporesponsiveness and Leads to Filarial Parasite Clearance In Vivo. J. Immunol. 2005, 174, 4924-4933. [CrossRef]

91. Bennuru, S.; Semnani, R.; Meng, Z.; Ribeiro, J.M.C.; Veenstra, T.D.; Nutman, T.B. Brugia malayi excreted/secreted proteins at the host/parasite interface: Stage- and gender-specific proteomic profiling. PLoS Negl. Trop. Dis. 2009, 3, e410. [CrossRef]

92. Tang, L.; Ou, X.; Henkle-Duhrsen, K.; Selkirk, M.E. Extracellular and cytoplasmic CuZn superoxide dismutases from Brugia lymphatic filarial nematode parasites. Infect. Immun. 1994, 62, 961-967. [CrossRef]

93. Ou, X.; Thomas, G.R.; Chacón, M.R.; Tang, L.; Selkirk, M.E. Brugia malayi: Differential susceptibility to and metabolism of hydrogen peroxide in adults and microfilariae. Exp. Parasitol. 1995, 80, 530-540. [CrossRef]

94. Anand, S.B.; Rajagopal, V.; Kaliraj, P. Brugia malayi thioredoxin peroxidase as a potential vaccine candidate antigen for lymphatic filariasis. Appl. Biochem. Biotechnol. 2012, 167, 1351-1364. [CrossRef]

95. Thomas, G.R.; McCrossan, M.; Selkirk, M.E. Cytostatic and cytotoxic effects of activated macrophages and nitric oxide donors on Brugia malayi. Infect. Immun. 1997, 65, 2732-2739. [CrossRef]

96. Kilgore, K.S.; Flory, C.M.; Miller, B.F.; Evans, V.M.; Warren, J.S. The membrane attack complex of complement induces interleukin-8 and monocyte chemoattractant protein-1 secretion from human umbilical vein endothelial cells. Am. J. Pathol. 1996, 149, 953-961. [PubMed]

97. Weinkopff, T.; Mackenzie, C.; Eversole, R.; Lammie, P.J. Filarial excretory-secretory products induce human monocytes to produce lymphangiogenic mediators. PLoS Negl. Trop. Dis. 2014, 8, e2893. [CrossRef] [PubMed]

98. Morchón, R.; Bazzocchi, C.; López-Belmonte, J.; Martín-Pacho, J.R.; Kramer, L.H.; Grandi, G.; Simón, F. iNOs expression is stimulated by the major surface protein (rWSP) from Wolbachia bacterial endosymbiont of Dirofilaria immitis following subcutaneous injection in mice. Parasitol. Int. 2007, 56, 71-75. [CrossRef]

99. Rajan, T.V.; Porte, P.; Yates, J.A.; Keeper, L.; Shultz, L.D. Role of nitric oxide in host defense against an extracellular, metazoan parasite, Brugia malayi. Infect. Immun. 1996, 64, 3351-3353. [CrossRef] [PubMed] 